\title{
Administrar justicia en la era tecnológica
}

\author{
Doing Justice in the Technological Age
}

\author{
Diego Medina Morales \\ Universidad de Córdoba \\ dmedina@uco.es
}

Resumen: El derecho, como mecanismo social para el diálogo y la resolución de conflictos, requiere, para conseguir sus fines u objetivos, del auxilio de instrumentos, consistentes, por lo general, en reglas de conducta y decisiones que aporten soluciones acerca del tráfico y la conservación de «bienes». Tales reglas y decisiones se tienen que apoyar, para resultar operativas y útiles, en el lenguaje (oral u escrito), así, mediante el uso de las palabras, se orientan las acciones de los operadores jurídicos y de cualquier otro sujeto de derecho. La técnica jurídica es un elemento auxiliar importantísimo de la ley, en consecuencia, cualquier avance tecnológico, que potencie la técnica contribuye a facilitar y mejorar la comunicación jurídica. El Derecho se presenta como un sistema de comunicación, como un lenguaje, susceptible de mejora tecnológica. En los últimos años, los poderes públicos y particularmente la Administración de Justicia (entendida, en este contexto, como el servicio de resolución de conflictos que el Estado pone al servicio de los ciudadanos) están incorporando los avances tecnológicos, que la nueva era digital ha aportado, para facilitar el tratamiento de la información y de la comunicación. En este proceso de adaptación tecnológica, el renovado sistema comunicacional permite a los ciudadanos comunicar más directamente con la maquinaria Estatal encargada de «administrar justicia». Actualmente, esto debería significar una mayor eficiencia en el tratamiento de los casos, un ahorro de tiempo, una disminución de los costes y un más fácil acceso a una justicia de mayor calidad.

Palabras clave: justicia; nuevas tecnologías; Derecho.
Abstract: The law, as a social mechanism for dialogue and resolution of conflicts, requires, to achieve its aims or objectives, the help of instruments that consisting, in general, in rules of behavior and decisions that provide solutions about traffic and conservation of goods. Such rules and decisions must be expressed, to be operative and useful, in a language (oral or written). Thus, using this words (law), should be oriented the actions of the legal operators (lawyers). The legal technique is a very important auxiliary element of the law, therefore, any technological advance, which enhances the technique, contributes to facilitate and improve legal communication. Law is presented as a communication system, as a language, susceptible to technological improvement. In recent years, public authorities and particularly the Administration of Justice (understood, in this context, as the conflict resolution service that the State puts at the service of citizens) are incorporating technological advances, which the new digital era has created, to facilitate the processing of information and communication. In this process of technological adaptation, the new communication system allows citizens to communicate more directly with the State machinery which is responsible of «administering justice». Currently, this should mean greater efficiency in the treatment of cases, a saving of time, a reduction in costs and easier access to higher quality justice.

Keywords: justice; new technologies; Law. 
Todo progreso tecnológico, en el momento de su aparición, ha sido temido e incluso rechazado. Y sabemos que cualquier innovación molesta porque cambia los órdenes constituidos.

Homo videns. La sociedad teledirigida.

Giovanni Sartori

\section{DERECHO Y COMUNICACIÓN}

E 1 derecho, como mecanismo social para el diálogo y la resolución de conflictos, requiere, como tantos otros oficios, de la ayuda de instrumentos para conseguir sus fines u objetivos; estos instrumentos, por lo general, consisten en reglas de conducta y/o «decisiones» que, atendidos los hechos sociales y en relación con tales instrumentos (institucionalizados) aportan soluciones acerca del tráfico y la conservación de «bienes»1. Tales reglas y decisiones se tienen, ineludiblemente, que apoyar, de alguna manera, para resultar operativas y útiles (entiéndase, buenos instrumentos al servicio del jurista) en el lenguaje (oral u escrito) -que es la primera forma natural y básica de comunicación del ser humano- para que, mediante el uso de las palabras (es decir de su verbalización y consecuente institucionalización), se orienten las acciones de los operadores jurídicos (ya en un marco institucional concreto, donde sus actos cobrarán significado) y las de cualquier otro sujeto de derecho, dando sentido jurídico a las relaciones sociales. Evidentemente el Derecho se presenta, desde esta perspectiva, como un sistema de comunicación, como un lenguaje (debidamente institucionalizado), que nos permite instituir el significado de nuestras acciones en el entorno específicamente jurídico en el que nos movemos y, por ello, interpretar nuestras acciones y poder establecer (si lo deseamos) una relación comunicativa (de naturaleza jurídica) con los demás ${ }^{2}$.

1 Para el Prof. Robles Morchón resultan esenciales al derecho cinco elementos que, básicamente, lo constituyen y, de los cuales, tres son básicos, «de estos conceptos que pueden servir de 'llave' para entender la realidad jurídica yo destacaría los siguientes: el concepto de decisión, el de norma. El de acción. El de institución y el de relación». Los citados tres son: la decisión, la norma y la institución, que como verá el lector aparecen inmediatamente en nuestro discurso. Vid. Robles, G., Teoría del Derecho. Fundamentos de Teoría comunicacional del derecho, Thomson Reuter, Aranzadi, Pamplona, 2015 (956 pp.), p. 76.

2 Observe el lector como ahora en nuestro discurso introducimos los dos elementos más a los que nos referimos en nuestra anterior nota, es decir, acción y relación, completando así el elenco referido por Robles en su obra. Ibid. 
Evidentemente, esta naturaleza comunicativa inherente al derecho, es lo que ha conducido al Prof. Robles Morchón ${ }^{3}$ en la estela de otros muchos autores, a asegurar que «el derecho es lenguaje», cuestión a la que ha dedicado casi tres décadas, de momento, hasta construir su Teoría comunicacional del Derecho. Ahora bien, como ya hemos insistido en otras ocasiones, a nuestro parecer, no resultaría demasiado acertado extraer de esa representación conceptual la impresión de que el derecho consista meramente en un cúmulo sistematizado y ordenado de normas escritas que, sólo por ello, deben ser cumplidas por sus destinatarios. Esta postura ordenalista y meramente normativa, reduce el concepto de derecho a la mera idea de un orden establecido al que hay que sujetar la voluntad de los destinatarios del mismo. Tal postura, sostenida con la simpleza que, por lo general, ha sido sustentado por el positivismo normativista, entra, sin duda, en contradicción con otras afirmaciones, no menos importantes, sobre las que se asienta y encuentra apoyo cualquier concepción sensata acerca del Derecho. Así, por ejemplo, es evidente que si las decisiones jurídicas (elementos, por otra parte, fundamentales de la Teoría

3 Uno de los postulados sobre los que se asienta la Teoría Comunicacional de Robles es en el binomio derecho-texto. Efectivamente para Robles el derecho es lenguaje y, sobre todo, es texto. Testimonio patente de este parecer se contiene en la siguiente afirmación sustentada por este autor en su Teoría comunicacional: «todo derecho es susceptible de ponerse por escrito». Ahora bien, en nuestra opinión, no podemos extraer de esta tajante afirmación una conclusión errónea; creemos que para Robles el derecho es texto, pero, a su vez, el derecho es mucho más que texto. Opinamos así puesto que cuando el autor bilbaíno sostiene tal afirmación consideramos que no se refiere tanto al derecho propiamente dicho (al menos en sus facetas fácticas y axiológica), sino que, más bien, se refiere al Ordenamiento jurídico, o todo lo más a la dogmática, es decir, a todo aquello que, en general, podemos percibir como parte de los instrumentos jurídicos, entiéndase por tales, aquellos instrumentos que auxilian al jurista en la actividad que le es propia (pues el Derecho será el resultado de tal actividad). Buena prueba de ello, como hemos reproducido hace unas líneas, la encontramos en el hecho de que el mismo autor sostenga que el derecho es susceptible de ponerse por escrito. Pues bien, si el derecho es susceptible de ponerse por escrito esto significa, necesariamente, que el derecho es una realidad que, pese a poder ser «susceptible» de ser recogida en un texto, si no es recogida, no necesariamente pierde su naturaleza. $O$, dicho de otro modo, si Robles pretendiese decir que el derecho es sólo y exclusivamente texto (aspecto normativo), hubiera omitido el término «susceptible» y hubiera sostenido, a secas, que el derecho es texto y no lo hace. También sostiene en páginas sucesivas que: «todo ordenamiento jurídico es un gran texto unitario que se compone de textos parciales (las distintas leyes, decretos, reglamentos, sentencias judiciales, etc.)». Robles, G., Teoría del Derecho. Fundamentos..., op. cit., p. 92. Obra que ha sido reeditada en cinco ocasiones más (la última edición es la sexta); 1. ${ }^{\text {a }}$ ed., Cívitas, Madrid, 1998 (376 pp.); 2. a ed., Thomson Civitas, Aranzadi, Cizur Menor, 2006 (435

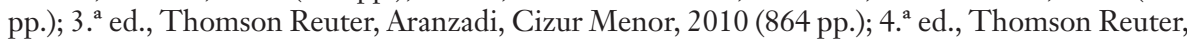
Aranzadi, Cizur Menor, 2012 (864 pp.); 5. ed., Thomson Reuter, Aranzadi, Cizur Menor, 2013 (976 pp.) (en lo sucesivo citamos de la sexta edición). 
comunicacional) se manifiestan mediante el lenguaje, no menos cierto es que una decisión no es sólo y exclusivamente lenguaje, sino que es mucho más. La decisión, base fundamental de cualquier sistema jurídico, se caracteriza, sobre todo, por ser, más allá de la estructura formal en que se manifieste, una resolución volitiva (es decir, el resultado de un acto de voluntad que «quiere») que se toma ante las muy distintas posibles opciones que se ofrecen en cada situación.

El Derecho, entonces, se presenta como un complejo sistema de comunicación que, como ya hemos sostenido en otras ocasiones ${ }^{4}$, sirve a sus interlocutores (a los sujetos que componen o forman parte de una sociedad) para cambiar o conservar «bienes». El Derecho funciona, pues, del siguiente modo: cuando algún sujeto, en sociedad, decide (toma la decisión) disponer de un bien para cambiarlo (o para conservarlo en su patrimonio), acomodará su comportamiento a las pautas de conducta indicadas por el Derecho siguiendo así las técnicas indicadas normativamente (es decir, consuetudinariamente o racionalmente, según el sistema de derecho que predomine en esa sociedad); tal comportamiento, adoptado según las normas, provocará el estímulo (jurídico) en quienes con él mantengan una relación (jurídica), de modo tal que su conducta encontrará una respuesta (jurídica) en el entorno, es decir, que su «oferta/demanda» encontrará la correspondiente «demanda/ oferta» que haga posible que se cierre el circulo comunicacional y que, en consecuencia, el bien objeto del negocio pueda transitar (comunicarse) de un patrimonio a otro o, en su caso, permanecer en el de origen (es decir, que si, por ejemplo, el emisor del mensaje trata de vender una casa, las acciones jurídicas emprendidas por él -vendedor- estimulen y encuentren al correspondiente destinatario -comprador-, que al cumplimentar la acción comunicativa permitirá la transferencia del bien llamado casa, comunicándose el mismo de un patrimonio a otro).

La decisión, pues, es un elemento esencial del Derecho, como también lo suele ser en cualquier otro ámbito comunicacional, y este aspecto, precisamente, pone de relieve su importancia, hasta el punto que puede afirmarse que la actividad jurídica por excelencia consiste, precisamente, en tomar decisiones (y, sobre todo, cuando la actividad es judicial, la decisión se produce acerca de lo justo o injusto), es decir, en juzgar, por lo que evidentemente «el juicio» es

4 Vid. entre otros mi trabajo «Validez y juridicidad en la Teoría Comunicacional del Derecho», en Teoria Comunicacional do Direito: dialogo entre Brasil e Espanba, Moeses, Sao Paolo, 2011, pp. 571-602. 
el elemento medular del Derecho ${ }^{5}$. Ahora bien, «el juicio» sólo existe si quien decide puede optar entre distintas soluciones ${ }^{6}$, puesto que «juzgar» es tomar una decisión definitiva sobre algo dudoso o contestable. De otro modo, si la acción de quien decide estuviera pre-dirigida y no pudiere más que desembocar en un único resultado, no contemplaríamos verdaderamente una decisión (a la que debe reconocérsele un carácter creativo o innovador) sino que ante nosotros se produciría un acto de mera aplicación mecánica (que no es más que referir a un caso particular lo que se ha dicho en un supuesto general). Aplicar, pues, no es decidir sino acomodar la norma al caso. Quien así obra no decide, sino que simplemente es un mero ejecutor ${ }^{7}$ en un proceso preestablecido, un mero autómata. Parece pues más que obvio que, aunque quien tome la decisión necesite del auxilio del lenguaje (incluso del texto) para expresarse, y aunque también necesite del auxilio de las técnicas jurídicas (las normas, entre otros instrumentos auxiliares) para materializar su decisión (emitiendo el juicio), el Derecho en sí mismo, es mucho más que lenguaje, es un diálogo social mediante el que se pretende resolver los conflictos de intereses que en

$5 \ll$ Respondeo dicendum quod iudicium proprie nominat actum iudicis inquantum est iudex. Iudex autem dicitur quasi ius dicens. Ius autem est obiectum iustitiae, ut supra habitum est. Et ideo iudicium importat, secundum primam nominis impositionem, definitionem vel determinationem iusti sive iuris. Quod autem aliquis bene definiat aliquid in operibus virtuosis proprie procedit ex habitu virtutis, sicut castus recte determinat ea quae pertinent ad castitatem. Et ideo iudicium, quod importat rectam determinationem eius quod est iustum, proprie pertinet ad iustitiam. Propter quod philosophus dicit, in V Ethic., quod bomines ad iudicem confugiunt sicut ad quandam iustitiam animatam.». SANTO TOMÁs, Suma Teológica, Secunda II, Quaestio, 60.

6 Es a lo que Robles se refiere cuando afirma: «Toda decisión implica una elección y, consiguientemente, la exclusión de las otras posibles alternativas. Decidir es elegir. Para elegir hay que estar convencido de que no se yerra o, al menos, de que la elección hecha es la menos mala. Para elegir entre varias alternativas hay que comparar. Y para comparar hay que valorar. El tema de la decisión nos lleva irremediablemente al de los valores, que son precisamente las pautas desde las cuales se valora o se enjuicia y, por tanto, se elige, esto es, se decide». Robles, G., Teoría..., op. cit., p. 102.

7 Precisamente esta era la creencia de la que participaron los autores de la escuela de la Exégesis y la que presidió el espíritu de la codificación. Incluso Jean-Etienne-Marie Portalis reacciona ante el Decreto Orgánico de 24 de agosto de 1790 que estableció en Francia el llamado référé législative (la remisión que debía hacer el juez de los puntos dudosos o ambiguos al Poder Legislativo para que la Asamblea respectiva diera la solución clara y precisa al asunto controvertido), y manifiesta que «Forzar al magistrado a recurrir al legislador, sería admitir el más funesto de los principios, sería poner de nuevo en vigencia entre nosotros la desastrosa legislación de los rescriptos, pues cuando interviene el legislador para pronunciarse en los asuntos nacidos y vivamente agitados entre particulares, no está más al abrigo de rebatos que los tribunales». PORTALIS, J.E.M., Discurso preliminar al Código Civil francés (Prólogo de M. Rivacova), Edeval, Valparaíso, 1978, p. 43. 
torno a la posesión y la transmisión de «bienes» se pueden originar en una sociedad. Para la comprensión de este aspecto resulta, pues, fundamental tener muy clara la distinción entre las categorías conceptuales que denominamos «decisión»y «aplicación».

Debe considerarse, pues, que el texto jurídico (contemplado como conjunto de instrumentos de que dispone el jurista a la hora de desarrollar su trabajo) se ofrece como un elemento que, aunque muy importante, es meramente auxiliar para la actividad decisoria, y que, evidentemente, cuando se afirma, como lo hace Robles en su Teoría Comunicacional del Derecho, que el derecho es un lenguaje, se está queriendo decir que, aunque lenguaje, sin embargo, es mucho más que texto. Por ejemplo, si nos detenemos a examinar la página 93 de la Teoría del Derecho de Robles, cuando este autor afirma que: «Decir que el derecho es lenguaje no supone defender una posición ontológica 'fuerte' (algo así como una definición de su 'esencia'). Significa tan sólo aceptar que esta cualidad del derecho puede servirnos como punto de partida para su análisis» ${ }^{8}$, apreciaremos que está poniendo de manifiesto esta particularidad que ofrece el llamado «Texto jurídico». No cabe duda que la forma en la que se presentan, generalmente, los instrumentos jurídicos (leyes, tratados, sentencias, etc.) se corresponde con un lenguaje de carácter regulativo o prescriptivo, pero no menos cierto nos parece que quien decide (el jurista y sobre todo el Juez) realiza una actividad psíquica (o volitiva) que, orientada por las normas y, a su vez, presidida por una cultura jurídica que se encuentra, entre otras fuentes, en la doctrina (jurisprudencial y científica), lo hace con el objetivo de tomar una decisión adecuada (justa) o, cuanto menos, como dice Robles, con la pretensión de tomar la decisión «menos mala», entre todas las probables.

Este inconfundible significado que en Robles adquiere el término «texto jurídico» y el hecho, inequívoco, de que el citado texto se refiera, no a todo el derecho, sino tan sólo a los instrumentos jurídicos que auxilian la decisión, es lo que, a nuestro parecer, lleva al autor de la Teoría Comunicacional del Derecho a afirmar sin reservas que: «El ordenamiento es el texto jurídico en bruto en su totalidad, compuesto por textos concretos, los cuales son resultado de decisiones

8 Robles, G., Teoría..., op. cit., p. 93. Y por si quedase temor a dudas añade acto seguido: «Incluso es posible combinar la idea de que el Derecho se manifiesta siempre en lenguaje con una tesis 'fuerte' acerca de la esencia del Derecho (como pueden ser, por ejemplo, la tesis de que el Derecho es 'hecho social' o es 'idea de justicia')». 
concretas» ${ }^{9}$ y a diferenciar, más adelante, a este texto jurídico bruto de lo que él llama texto jurídico elaborado, que no es otro que el texto que resulta de la labor de los juristas ${ }^{10}$, es decir la doctrina jurídica (en su doble faceta jurisprudencial y científica). En parte, como puede observarse, Robles, huyendo de una perspectiva puramente normativa y positivista, retoma, a nuestro parecer, el viejo concepto que de Derecho tenían los juristas pre-ilustrados; un derecho aplicado (o mejor dicho, creado) no en ciego y exclusivo seguimiento de la norma positiva (por el solo hecho de estar ésta promulgada por el Estado, es decir, por las voluntades concretas de quienes mandan y «cobran por mandar») sino un derecho elaborado por juristas (es decir, creado) en virtud de normas meramente orientadoras y «justo» gracias a la labor de reconstrucción continua y de adaptación al «caso concreto» que los propios juristas, con su diaria labor, realizan a partir del oportuno ordenamiento jurídico. Por tanto, Robles nos refiere un derecho de juristas, fluido y descentralizado, un derecho de opiniones y controversias (que se pone de manifiesto a través de la doctrina jurídica), entre las cuales el juez debe investigar, al objeto de tomar la decisión más justa, es decir, más adecuada al caso concreto, escapando de una ramplona y simple aplicación de un «derecho» dictado (ordenado) por el legislador. Un derecho, hecho por juristas y no por políticos, un Derecho construido por quienes verdaderamente representan al pueblo ante los Tribunales y no por quienes dicen representarlo (y generalmente no lo representan) en los órganos legislativos.

Así pues, el Ordenamiento, propiamente dicho (la mera suma de normas), no es identificable plenamente con el Derecho (como pretendieron hacer creer ciertos representantes del positivismo a lo largo del siglo XX). El mero ordenamiento (texto jurídico bruto como lo llama Robles) no constituye más que un conjunto de instrumentos a los que el jurista suele recurrir para forjar, con su creativa actividad de concreción, el Derecho (ahora sî), que no es otra cosa que el resultado de la propia actividad de los juristas. El Derecho pues, no es la norma, la norma es, tan sólo el instrumento que (entre otros) el jurista usa cotidianamente para hacer Derecho; de tal modo que el Derecho es el resultado de la actividad de los juristas, de igual modo que podemos sostener que la Medicina es el resultado de la actividad de los médicos, o la Carpintería el resultado de la actividad de los carpinteros. Pocos confundirían la Medicina con los protocolos médicos o con el instrumental de una sala ope-

9 Robles, G., Teoría..., op. cit., p. 139.

10 Ibid., p. 142. 
ratoria; todos sabemos que la Medicina es un arte que practican los médicos; del mismo modo, pues, ha de predicarse que el Derecho no es otra cosa que el arte que practican los juristas.

El Ordenamiento jurídico está formado, sin lugar a la más mínima duda, por instrumentos importantes, pero instrumentos que, por si mismos no significan nada, supuesto que sólo son parte de las herramientas que el jurista, habitualmente, usa en su particular «quehacer» («quehacer» que precisamente da sentido a esos instrumentos) y que, en consecuencia, el jurista aprovecha y usa para materializar su actividad «decisoria», ésta última sí verdadera productora del Derecho. El resultado de tal actividad (de la labor de los juristas) es la que orienta el «sistema»; este es el motivo de que tal actividad, cobre una vital importancia a la hora de la construcción dogmática del Derecho, es decir, de una labor de reconstrucción hermenéutica del ordenamiento ${ }^{11}$.

La mutua interacción entre ordenamiento y sistema, es decir, entre ley y actividad interpretativa y doctrinal, es la que permite hacer del Derecho un sistema verdaderamente comunicativo como sostiene Robles; es decir, es la actividad de los juristas la que permite aparecer al Derecho como un sistema capaz de consentir que, en sociedad, se comuniquen bienes y que éstos se protejan igualmente, mediante el sostenimiento de relaciones capaces de tejer un mecanismo institucional de tráfico.

Definitivamente cabe concluir que el Derecho es, sobre todo, una actividad de juristas que, al ejercitar la facultad que le es propia, conforme al sistema institucionalmente establecido, van simultáneamente produciendo y perfeccionando sus instrumentos en un proceso circular o en una «espiral» de naturaleza hermenéutica. Los juristas usan los instrumentos jurídicos (normas, dogmática y precedentes) para comunicar y/o conservar bienes, y usando tales instrumentos (normas, dogmática y precedentes) los crean y recrean, los implementan y los perfeccionan, mejorando el sistema. Los sistemas jurídicos, en consecuencia, resultan ser plurales (poseen esa cualidad

11 Es lo que Robles, en la Teoría comunicacional del Derecho, llama «texto elaborado», construida por los propios juristas mediante el perfeccionamiento de la doctrina jurisprudencial y de la ciencia jurídica. «Pensar que el ordenamiento es, sin más, sistema, es efectivamente un prejuicio de la mentalidad legalista, que identifica el derecho con la ley, y se hace del texto de ésta una imagen que no es real, adscribiéndole las cualidades de coherencia, plenitud (en el sentido de ser completo), perfección del lenguaje, rigor conceptual, etc.» y añade, por si queda duda: «Esta imagen del ordenamiento corresponde a una imagen del legislador que hace tiempo entró en crisis». Ibid., p. 146. 
tan buena que es el pluralismo y la diversidad), ya sea desde el punto de vista geográfico como temporal, por esta razón no puede admitirse que exista un único sistema de derecho (un único mecanismo para conservar o comunicar bienes, como pretendió en normativismo-positivista del XIX, positivismo totalizador y totalizante) como, igualmente, no existe un único lenguaje (un único mecanismo para conservar o comunicar ideas). En general los sistemas de comunicación (de ideas o de bienes) están asociados a la evolución cultural de cada pueblo. De aquí el paralelismo entre la lengua y el derecho (ambos evidentemente productos culturales) paralelismo muy notorio y que se ha puesto de relieve, desde hace mucho tiempo, por diversidad de autores; particularmente, como todo jurista sabe, Savigny señaló que ambos son productos culturales elaborados por el Volksgeits, de ahí sus grandes similitudes (muy particularmente en la correlación existente entre derecho-ley y lenguagramática). Pero conviene, a estas alturas, matizar también la diferencia entre ambos sistemas comunicativos, puesto que mientras que el objetivo de la lengua (o del lenguaje según se prefiera) es transmitir y conservar ideas, el objetivo del derecho es transmitir o conservar todo aquello a lo que los juristas denominan bienes jurídicos (fortunas, riquezas, patrimonios, peculios, rentas, heredades, posesiones, valores, mercancías, negocios, transacciones, utilidades, provechos, títulos, etc.).

\section{TÉCNICA JURÍDICA}

Hemos puesto de manifiesto, hasta ahora, el modo en que el Derecho opera o funciona, como mecanismo de comunicación, para permitir, a quienes lo utilizan, conservar o transmitir «bienes»; también hemos insinuado ya que para cumplir su cometido el Derecho procede de forma similar a como en general lo hace el lenguaje -o la lengua-, práctica (la de hablar o escribir), ésta última, que, como sabemos, también faculta, a los sujetos que la usan, para conservar o transmitir (mediante soportes físicos, y hoy día también, mediante soportes informáticos) «ideas».

Ahora bien, llegados a este punto, cabe preguntarnos ¿de qué instrumentos se vale el Derecho para comunicar «bienes»? ¿A qué nos referimos cuando decimos instrumentos jurídicos? En definitiva, nos debemos preguntar ahora cuales son las técnicas específicas de las que se valen los juristas para llevar a cabo su actividad (su arte) consistente en conservar (proteger) o transmitir (comunicar) los «bienes». 
La técnica jurídica puede ser definida como un saber práctico, propio de juristas, que consiste en la destreza en el manejo de los instrumentos (jurídicos) que hacen posible la comunicación y conservación de los «bienes» (también jurídicos) entre los sujetos que componen una sociedad determinada. Es por tanto un saber instrumental que requiere, entre sus operadores, una especial destreza y un especial conocimiento tanto de los instrumentos jurídicos como tales, como de sus posibles utilidades o usos ${ }^{12}$. También exige una especial destreza en su uso a los efectos de poder alcanzar los fines comunicativos que en cada caso se persigan.

Es este un saber que pese a ser eminentemente práctico, sin embargo requiere en parte de algún previo conocimiento teórico; en este sentido, se puede afirmar que, por lo general, es frecuente que al jurista le preocupe más el «saber hacer» que propiamente el «hacer»; el «hacer», sin embargo, en la práctica, como es lógico, toma un protagonismo relevante, puesto que la técnica es siempre medio o instrumento para el desarrollo de una acción que implica necesariamente la habilidad y destreza que hace posible un resultado deseado. Se trata, pues, de un saber que supone la adecuada utilización de instrumentos que han de rendir útiles al resto de los saberes teóricos.

La técnica jurídica constituye, además, un saber especializado, es decir, sus operadores mediante su rutinario uso van adquiriendo gran destreza y habilidad en el manejo de instrumentos jurídicos especializados, razón ésta por la que, por lo general, terminan por convertirse en especialistas (a veces incluso en partes o sectores muy concretos del ordenamiento ${ }^{13}$. Se trata, como vemos, de un saber eminentemente práctico pues, como ya hemos dicho, consiste en un «saber hacer» con vocación de materializarse en «hacer»; motivo éste por el que cabe afirmar que se trata de un saber, fundamentalmente, conocedor de rutinas o protocolos (por lo que requiere de reglas o procedimientos que faciliten su uso).

De todo lo expuesto podemos concluir, intentando hacer un paralelismo que nos parece útil a efectos comprensivos, que la técnica jurídica (con todas

12 Vid. Vallet de Goitisolo, J.B., Manuales de metodología jurídica (vol. III), Colegios Notariales de España, Madrid, 2004, pp. 271 y ss.

13 Vid. Elías de Tejada, F., Tratado de Filosofía del Derecho (tomo II), Universidad de Sevilla, Sevilla, 1977, pp. 17 y ss. Elías de Tejada, al desarrollar su teoría de los saberes jurídicos, describió este tipo de saber (el técnico) y aunque se pliega algo al normativismo, tan al uso en su época, su propuesta nos parece una buena representación del significado y el papel que adquiere la técnica respecto al Derecho. 
sus reglas inherentes) es al Derecho algo equivalente o parecido a lo que la gramática ${ }^{14}$ es a la lengua.

Cuando de la comunicación lingüística se trata, no resulta frecuente (y si lo fuera sería absolutamente erróneo) confundir la gramática y la lengua ${ }^{15}$ (es decir, que, en este ámbito de la comunicación, sabemos distinguir o diferenciar con nitidez, y sin necesidad de ser especialistas, entre los conceptos gramática y lengua, o por decirlo todavía más claro, distinguimos muy bien entre las «reglas de la lengua» respecto a la «lengua misma»). Sin embargo, frecuentemente, cuando hablamos de Derecho solemos confundir a éste con las técnicas que lo auxilian (es decir, con las reglas del derecho), confundiendo ambas cosas.

La lengua es un mecanismo de comunicación que, en esencia se hace y rehace cotidianamente a través de su uso por el pueblo (mediante el uso que sus operadores hacen de ella), de modo que es producto cultural del Volksgeist ${ }^{16}$; sus reglas (su lógica constructiva, entiéndase) las hacen los individuos y las colectividades mediante la consolidación de los hábitos y costumbres, que se institucionalizan a través de su inveterado uso, es decir, las reglas de una lengua se desarrollan mediante los hábitos de un pueblo a través de su peculiar «manera» de hablar y, sólo luego, los especialistas en lengua las reconocen, las sistematizan y las elevan a reglas gramaticales. Cuando estudiamos (cuando la estudian los especialistas) una lengua (y no tanto cuando la usamos) lo que intentamos es racionalizar las reglas y principios que rigen la forma de usar y organizar las rutinas de esa lengua, por parte de la concreta comunidad que la emplea; el resultado que se obtiene entonces es precisamente la Gramática. Por este motivo la Gramática (particularmente la que se conoce como «gramática normativa») se puede definir como aquella ciencia (dogmática) que define los usos correctos de una lengua mediante preceptos.

14 El Diccionario de la Real Academia de la Lengua Española, define en su primera acepción a la gramática del siguiente modo: «Ciencia que estudia los elementos de una lengua y sus combinaciones.». Además, define a la «gramática normativa» como: «gramática que define los usos correctos de una lengua mediante preceptos.».

15 El Diccionario de la Real Academia de la Lengua Española, define en su segunda acepción a la lengua del siguiente modo: «Sistema de comunicación verbal y casi siempre escrito, propio de una comunidad humana.»

16 Sobre el hecho, por otra parte, muy conocido, de que Savigny intentara hacer más inteligible su teoría sobre el origen del Derecho en la conciencia popular sirviéndose de la comparación con el desarrollo del idioma, puede verse: Contreras, F. J. «La idea de Espíritu del Pueblo en F.C.V. Savigny», Anales de la Cátedra Francisco Suárez, 35 (2001), 161-187, particularmente página 176. 
Su función no es otra que organizar el sistema lingüístico dándole un orden lógico general.

Pues bien, como resulta más que evidente, la lengua es un mecanismo de comunicación y la gramática es, tan sólo, el conjunto de reglas (técnica) referenciales para que sus usuarios, siguiéndolas, adquieran más fácilmente la técnica de comunicar mediante esa lengua y, consecuentemente, puedan hacerlo; además la lengua es un sistema o mecanismo de comunicación que usa cotidianamente cada particular comunidad, es decir, es un mecanismo de naturaleza singular, histórica y cultural, o dicho de otro modo, que se conforma o nace de modo tradicional y consuetudinario en cada comunidad particular (de ahí la pluralidad o riqueza de lenguas). Sin embargo, la gramática no es un producto popular ni tradicional, la gramática es el saber (universal) que trata de racionalizar y explicar el uso de las lenguas para que de este modo resulte mucho más fácil su correcto aprendizaje y uso, de modo que la gramática puede (como sistema) ser aplicada a varias lenguas; la gramática es, pues, el producto de los académicos que estudian el uso que el pueblo hace de la lengua tratando de reducirlo a normas o reglas gramaticales. Es decir, la gramática es un conjunto de recursos técnicos que sistematizan y deben facilitar el ejercicio de la lengua. Por tanto, lengua y gramática no se confunden, y si bien es cierto que la gramática es un magnifico instrumento auxiliar de la lengua (a la que podemos recurrir en caso de necesidad para despejar alguna duda acerca del uso adecuado de un idioma o lengua), no resulta menos cierto que la gramática (como recurso técnico construido mediante el dictado de la «voluntad» de reconocidos académicos que representan la autoridad en materia de lingüística) no es un sistema normativo mediante el que admitamos que se pueda imponer a un pueblo el modo en cómo debe de comunicar mediante su lengua; o dicho de otro modo, nadie podría considerar lógico o natural (aunque no resulte imposible del todo) que los académicos de una Institución de la lengua (por ejemplo, la Real Academia de la Lengua en España, por muy democráticamente que resultasen elegidos y por muy representantes de la voluntad popular que fuesen en materia de lengua) pudieran (como legisladores soberanos de la lengua y en representación del pueblo) reformar a su antojo (por muy racional que fuera su intención) el modo de hablar de una comunidad o pueblo valiéndose, además, para ello de la posibilidad de decretar e imponer coercitivamente una gramática mediante la imposición de sanciones.

La gramática, en definitiva, no es otra cosa que un buen instrumento al servicio de la lengua, que, como es obvio, pretende sistematizar-representar y 
reglamentar- la peculiar forma que una comunidad tiene de comunicarse mediante el habla y no, en modo alguno, un método para imponer como «deba o no deba comunicarse una determinada comunidad».

Pues bien, si comparamos la lengua y el derecho, ambos productos culturales tendentes a fomentar y hacer posible el intercambio de «ideas»-uno- o de «bienes»-el otro-, puede afirmarse que la gramática es a la lengua, lo que el ordenamiento legislativo es al derecho, es decir, ambos son instrumentos auxiliares que orientan la labor de quienes deben usar esos mecanismos de comunicación y, en consecuencia, facilitan la labor de sus operadores

El hecho de que la gramática, como hemos sostenido, sea un instrumento auxiliar de la lengua y que, como queda claro, esta última no resulte ser producto de aquella primera, sino que, por el contrario, la gramática encuentra su justificación en la lengua -puesto que la lengua, como hemos sostenido, sólo la crea el pueblo, mediante su uso, y la refuerza fundamentalmente la actividad que los literatos hacen, a lo largo de los tiempos, también mediante su uso (en la construcción literaria, lo que favorece una mayor difusión)- se corrobora, por ejemplo, con el fracaso que experimentó la única tentativa histórica que, durante el siglo XIX, pretendió imponer una lengua racional (artificial) universalizante. Nos referimos, claro está, al Esperanto ${ }^{17}$. El rechazo que originó la importante reacción popular frente a tal tentativa -tan a la moda- de imponer un modelo «racional-ideal» de lengua, por muy fundada y ventajosa que dicha tentativa fuere, produjo el inexorable fracasó de ese experimento; un fracaso ligado, por supuesto, a la dificultad que manifiestan los pueblos o comunidades para abandonar sus lenguas maternas, pues éstas (aún, quizá, poco racionales, «excesivamente» tradicionales y, a veces, excesivamente primitivas o rudimentarias -como sucede, por ejemplo, con el vasco ${ }^{18}-$ ) cotidianamente,

$17 \mathrm{El}$ esfuerzo que durante más de un siglo han realizado los esperantistas de todo el mundo, de momento no ha encontrado recompensa. El prologuista de la versión española de la conocida obra de Auld, William, escribía en su prólogo: «La presente obra es la traducción española de un informe que la Asociación Universal de Esperanto encargó a uno de los mejores expertos para conmemorar el centenario de este idioma. En principio, el libro está concebido para un público no esperantista que desee información sobre la lengua auxiliar internacional, y por eso su traducción merece todos los parabienes...» AULD, W., El esperanto: fenómeno de la comunicación, Esperanto - Liceo de Madrid, Madrid, 1992, p. 7.

18 Sobre el carácter rudimentario del euskera y la necesidad de préstamos terminológicos de esta lengua para confrontar ciertos ámbitos técnicos, científicos y filosóficos, puede verse, entre otros, COTERÓN AgORRIA, I. «Apuntes de filosofía del euskara II: problemas termino-transcriptivos», en Euskalingua, 7 (2005), pp. 174-187. 
sin embargo, se manifiestan útiles y suficientes para que el pueblo pueda comunicarse. El pueblo, pues, en lo que se refiere, al menos, a la producción de la lengua como medio de comunicación, no ha renunciado jamás a su protagonismo y, hasta ahora, ningún Estado ha conseguido arrebatar (secuestrar) al pueblo la prerrogativa de su producción (ni siquiera, como sabemos, el franquismo logró privar a ciertos territorios españoles del uso de sus lenguas tradicionales; aunque, por el contrario, en España, ya desde Felipe V, si se privó a ciertos territorios de sus derechos). El único hipotético modo mediante el cual una determinada gramática -olvidando su papel auxiliarpodría haberse impuesto sobre alguna particular lengua -para modificarla manu militari- hubiera sido mediante la posibilidad de forzar a los destinatarios a observar las normas gramaticales mediante el uso de sanciones o medios represivos -impuestos contra el consenso popular- para obligarles así a admitir un uso diverso; pero este método (sí llevado a la práctica, por el legislador soberano, para imponer «su» legislación racional sobre las normas tradicionales y populares) hasta el día de hoy no ha prosperado, y ningún «poder» ha osado abiertamente a hacerlo, de modo que si algunos pueblos perdieron su lenguaje fue tan sólo por el desuso, la adquisición de nuevos hábitos, la modificación tácita y la evolución.

El derecho, sin embargo, si ha sufrido tal proceso (la sustitución de las tradiciones por la Ley) y tras la revolución liberal, como sabemos, se suprimieron, primero mediante la codificación y más tarde a través del constitucionalismo, los derechos históricos, es decir, aquellos derechos (o libertades concretas) que habían surgido a lo largo de los siglos mediante la costumbre popular (tacitus consensus populi). Aunque, de todos modos, el triunfo (no poco sangriento) de la Ley, no supuso la total ruptura con el derecho tradicional, pues como tiene dicho Herrero de Miñón «incluso cuando, respondiendo a la más simplista de las visiones (la ley) pueda ser sólo voluntad del legislador (la ley) utiliza, en frase de Windscheid, la 'sabiduría de los siglos que nos han precedido'. Puesto que, decía Savigny, 'no crea cada tiempo de por sí y arbitrariamente su propia vida, sino que ella se produce en indisoluble comunidad con todo el pasado'» ${ }^{19}$. Lo cierto, en cualquier caso, es que a partir del momento que marca la revolución liberal, el pueblo no fue durante más tiempo ya el protagonista de la creación de su derecho, y a partir de entonces el Estado

19 Herrero de Miñón, M., Idea de los derechos históricos, Real Academia de Ciencias Morales y Políticas, Madrid, 1991, p. 20. 
-y la «Razón Pura», sobre la que supuestamente se asienta su producción normativa- mediante su poder legislativo (teórico representante de la soberanía y conformador de la «Voluntad General») impuso las normas (modificando paulatinamente algunas y no tan paulatinamente otras -por ejemplo las desamortizadoras-) mediante las cuales convenía (sobre todo, desde entonces, a los imperantes o clase política dirigente y lobbies con ella relacionados) se comportase el pueblo.

Este paralelismo entre lengua y derecho -coherente y fácil de comprender puesto que como vemos tanto la lengua como el derecho son sistemas de comunicación desarrollados en un entorno cultural concreto- nos permiten ilustrar con cierta claridad el papel que la ley tiene -o, al menos, «debiera tener»- respecto al derecho (como la gramática frente a la lengua), como nos permite también advertir que -bastante interesadamente- los posicionamientos positivistas modernos y sus consabidos razonamientos han ignorado este importante detalle (seguramente, en la mayor parte de los casos, a conciencia) atribuyendo así a la ley un papel no tanto de instrumento sistematizador y auxiliar del derecho, sino de fuente y directo productor de derecho (de «su derecho» ${ }^{20}$, convendría matizar $)^{21}$.

Evidentemente, como hemos puesto anteriormente de manifiesto, estos dos sistemas comunicativos, lengua y derecho, presentan gran similitud en sus mecanismos de funcionamiento, ahora bien, como es lógico, hay una neta diferencia entre ambos, pues trátese de mecanismos comunicacionales diversos; así pues, mientras que la lengua es un mecanismo de comunicación usado (actividad lingüística humana) con la finalidad de comunicar y conservar «ideas», el derecho, por su parte, es un medio de comunicación usado (actividad jurídica humana), como ya hemos dicho, con el cometido de conservar o transmitir «bienes». Motivo suficientemente importante para que las técnicas comunicativas sobre las que se sustenten tengan marcadas diferencias.

20 Fernández-EsCalante, M., Los imperantes (y su sequito) y el imperio (de la-«su»-ley): Con un discurso de circunstancias «sopra il Governo Misto», Adhara, Granada, 1991.

21 De un derecho que ya no sería jamás producto de los usos consuetudinarios (de los hábitos) del propio pueblo, sino de la «voluntad» de la clase política dominante (alzada al poder mediante falsos mecanismos democráticos) y en beneficio de su propio interés. Nada de extraño tiene que hoy el pueblo se queje de la corrupción de la clase política que nos gobierna y de las leyes injustas que nos imponen. 


\section{LA ERA DE LA INFORMÁTICA Y LOS CAMBIOS JURÍDICOS}

$\mathrm{Si}$, como venimos sustentando, desde los preliminares o comienzos de este trabajo, la técnica jurídica es un elemento auxiliar importantísimo para hacer útil al derecho (hasta el punto de poder compararla con la técnica lingüística o con la gramática, como hemos hecho) parece obvio que, tratándose fundamentalmente de una técnica, lógicamente y salvo error, cualquier avance o cambio tecnológico que nos ofrezca el paso del tiempo venga a facilitar y, consecuentemente, a mejorar la comunicación jurídica entre sus operadores; es decir, lo razonable es que las mejoras tecnológicas contribuyan a mejorar la actividad jurídica para que ésta resulte más efectiva y rápida. Ésta, y no otra, es la razón por la que los cambios tecnológicos (que se han desarrollado a lo largo de las últimas décadas con el avance de la computarización y la aparición de redes), pese a haber hecho más compleja la comunicación lingüística, a su vez la han rendido, sin lugar a dudas, más eficaz, poderosa y rápida. No cabe la menor dudad que los importantes cambios tecnológicos que se han producido en las últimas décadas están influyendo decisivamente en ambos sistemas de comunicación, tanto en la lengua como en el derecho.

Si nos fijamos en la comunicación lingüística y en su evolución desde que se han implantado las nuevas técnicas de comunicación a nivel global, podemos observar el cambio que ha sufrido ésta. Como sostuviera MacLuhan, en su conocida obra La Galaxia Gutenberg, el sistema de comunicación a nivel global ha cambiado de forma tal que, en cierto modo, ha vuelto a presentar, de forma manifiesta, aspectos de la vieja sociedad pre-tipográfica. Esta singular circunstancia es la que permitió a este autor elaborar el, ya tan difundido, concepto de aldea global ${ }^{22}$. Por su parte Walter J. Ong, en su libro Oralidad y escritura. Tecnologías de la palabra, nos introduce en la discusión de los avances tecnológicos a través de la diferencia entre la oralidad y el conocimiento mediante la escritura, subrayando la dificultad que existe

22 «Lo que comenzó como una 'reacción romántica' hacia la integración orgánica puede o no haber acelerado el descubrimiento de las ondas electromagnéticas. Pero es cierto que los descubrimientos electromagnéticos han hecho resucitar el 'campo' simultáneo en todos los asuntos humanos, de modo que la familia humana vive hoy en las condiciones de 'aldea global'. Vivimos en un constreñido espacio único, en el que resuenan los tambores de la tribu». MacLuHAN, M., La Galaxia Gutenberg, Digital, pp. 21, <http://www.ub.edu/procol/sites/default/files/LaGalaxia-Gutenberg-Marshall-Mcluhan-.pdf> (12 de abril de 2017). 
para concebir una cultura sin escritura y comparando entre «culturas orales y las caligráficas $\gg^{23}$.

No cabe la menor duda de que los sistemas de comunicación han cambiado con la revolución tecnológica en la era electrónica y, evidentemente, nuestros sistemas de comunicación han perdido ciertos aspectos tópicos que les habían caracterizado durante toda la época tipográfica. Un ejemplo claro de ello es que en las escuelas nuestros niños ya no usan aquellos libros de texto clásicos que nos acompañaron en las aulas a aquellos otros niños de nuestra generación o de las que nos precedieron. Libros llenos de letras y con pocas representaciones gráficas (las justas), libros que, como diría Giovani Sartori, estaban destinados a ser «leídos» y no «vistos», dedicados al homo Sapiens y no al homo Videns ${ }^{24}$, libros llenos de conceptos y con pocas imágenes. Sin embargo, hoy día los niños en las escuelas trabajan no ya con libros, sino con ordenadores llenos de informaciones gráficas y con pocos contenidos conceptuales (palabras) o, todo lo más, con libros llenos de imágenes, donde predomina la información que precisa ser vista y no tanto leída. La llamada multimedia ha eclipsado -creo, con Sartori, que de momento para mal-a las viejas técnicas de comunicación escrita. Por otra parte, la comunicación es cada día más inmediata, e incluso las nuevas técnicas han cambiado sustancialmente el uso de la tipografía. Mecanismos de comunicación como WhatsApp, Line o Viber, entre otros muchos, hacen que nuestros jóvenes (o, mejor dicho, nuestros niños, por las edades tan tempranas en las que empiezan a usarlos) comunique hoy con un modelo tipográfico consistente en frases cortas, abreviaturas, acrónimos, emoticones etc., que nada tienen que ver desde luego con la comunicación epistolar que hasta hace 30 años solían tener las personas mediante las tradicionales cartas.

Naturalmente, estos cambios han alcanzado también al mundo jurídico y, hasta cierto punto, han cambiado su escenario, a la par que se han ido produciendo los avances tecnológicos en los últimos tiempos, nuestros tribunales han dejado de «leer» (aunque de una forma más ralentizada que en otros terrenos) para empezar a «ver». Un ejemplo claro de este fenómeno lo podemos evidenciar en la falta de relevancia que hoy día adquiere en nuestros Tribunales

23 Ong, W.J., Oralidad y escritura. Tecnologías de la palabra, Fondo de Cultura Económica, México, 1987, 2. ${ }^{\mathrm{a}}$ imp. 1997, p. 11.

24 Sartori, G., Homo Videns. La sociedad teledirigida, Taurus, Buenos Aires, 1998. «Así pues, el cambio de agujas se ha producido por el hecho de informarse viendo», p. 35. 
verbalizar la mayor parte de actos procesales, es decir, levantar acta literal de los juicios, declaraciones de testigos, peritajes, etc., todo esto, naturalmente, se sigue recogiendo, pero mediante la digitalización de imágenes que, posteriormente, su Señoría (antes de resolver) puede volver a «ver» (que no «leer») y que se conservan igualmente a disposición de los Tribunales de Apelación, que ahora también pueden «ver» las actuaciones que tuvieron lugar en Primera Instancia. Parece ser que hemos vuelto, más que nunca, a la sencilla, pero muy importante, idea de la inmediación (al menos virtual) y al elemental mecanismo de audiencia (síntoma de oralidad), trascendiendo, o tal vez huyendo, de la época en la que predominó de forma relevante el procedimiento escrito ${ }^{25}$. Las Audiencias, reales o virtuales, se imponen sobre el material escrito. Hasta hace unos años, para practicar, por ejemplo, una prueba testifical en cualquier sede judicial que no resultase ser la del Tribunal competente, se requería la formalización de un complejo procedimiento escrito que daba comienzo mediante exhorto. Éste se dirigía al Juzgado donde residiera el testigo, acompañado de un pliego de posiciones (o preguntas), una vez convocado el testigo, y con participación de las partes (si lo estimaban oportuno), en presencia del Sr. Secretario judicial y de su Señoría se evacuaban las preguntas levantando acta (escrita) del trámite donde constaban todas y cada una de las respuestas dadas al correspondiente ordinal, acta que se remitía inmediatamente al titular del Juzgado exhortante. Hoy todo este procedimiento es muy diferente ${ }^{26}$, mucho más sencillo y, tal vez, más seguro y eficiente; es suficiente una videoconferencia (telepresencia) ante el Sr. Secretario del Tribunal para que el Juez instructor de la causa pueda (cumpliendo virtualmente el principio de inmediación) ver la celebración de la prueba en directo (y en diferido cuantas veces más lo quiera o lo precise). Sirva este ejemplo, uno de muchos, para ilustrar tantos otros que se producen a diario en las sedes de nuestros Tribunales. Todo esto empezó a materializarse en España con la entrada en vigor de la nueva Ley de Enjuiciamiento Civil $(1 / 2000)^{27}$, que pretendido modernizar nuestro procedimiento judicial civil con el resultado de una «tutela

25 Esta circunstancia no ha pasado desapercibida al legislador que en la elaboración de la nueva Ley de Enjuiciamiento Civil ha dado una mayor relevancia a los actos orales que a los escritos, dando un mayor contenido de oralidad a todos los juicios de primera instancia. Vid. MonTERo AroCA, J., «La nueva Ley de Enjuiciamiento Civil española y la oralidad», Derecho PUCP, 53 (2000), pp. 583-668.

26 Fons RodríguEZ, C., «La videoconferencia en el proceso civil (la telepresencia judicial)», en Oralidad y escritura en un proceso civil eficiente (Coloquio de la Asociación Internacional de Derecho Procesal, 2008), Universidad de Valencia, Valencia, 2008, vol. 2, pp. 53-60.

27 Ley 1/2000, de 7 de enero, de Enjuiciamiento Civil, BOE, n. ${ }^{\circ}$ 7, de 08/01/2000. 
judicial» que se demore solo lo justo, es decir, ordenando actuaciones concisas para preparar la sentencia, tratando de garantizar su acierto. Las cuestiones procedimentales más sobresalientes en el nuevo diseño procesal las componen la vista en el juicio verbal, y la audiencia previa al juicio y el juicio mismo, en el juicio ordinario. De manera que, sin dejar de lado el papel que mantiene la escritura en el nuevo sistema procesal, es claro que el legislador español ha establecido procedimientos inspirados predominantemente en la oralidad.

$\mathrm{Y}$ éste se nos antoja, precisamente, un claro síntoma del cambio tecnológico y de su influencia en nuestro sistema jurídico, las nuevas tecnologías están haciendo predominar al lenguaje oral sobre el escrito, o tal vez sea más preciso matizar, como ha referido Sartori, un lenguaje inclusivo visual ${ }^{28}$ que ha relegado a un segundo plano al lenguaje escrito.

Otro elemento que ha potenciado las novedades tecnológicas aportadas por la electrónica es la inmediatez de la comunicación. Hoy día los comunicados se producen en «tiempo real», y este, precisamente, es uno de los principales factores que nos acercan al concepto de aldea global. Emisor y destinatario están muy cercanos (espacio-temporalmente) al menos de forma virtual. Desde que se produce el mensaje hasta que llega a su destinatario pueden pasar décimas o fracciones de segundo. Por otra parte, no podemos olvidar que ese aspecto ha influido colateralmente, pero de forma decisiva, a potenciar el principio de publicidad ${ }^{29}$ (con el consiguiente problema de la defensa de la privacidad y el derecho a la intimidad). Como suele ocurrir en el lenguaje oral, nuestras conversaciones (virtuales) hoy día pueden ser más fácilmente escuchadas por el resto de las gentes. La hermeticidad de la comunicación se está perdiendo y en nuestra aldea Global es mucho más difícil que podamos guardar los secretos frente a la comunidad. Este fenómeno ha

28 Que, por otra parte, en el mundo jurídico (judicial) nunca faltó del todo. Un ejemplo claro de ello lo tenemos en la importancia que en algunos procedimientos tenía la diligencia de inspección ocular, si bien es cierto que las técnicas del pasado sólo podían hacer que esa diligencia (de naturaleza fundamentalmente visual) adquiriera permanencia mediante su reflejo en un acta debidamente verbalizada (por lo tanto, escrita). Hoy día, sin embargo, cualquier diligencia de inspección ocular puede también recogerse mediante imágenes no solamente fotográficas, sino de video e incluso posteriormente realizar una recreación virtual por los departamentos de investigación especializados en esas tareas. Así pues, el predominio actual de la imagen sobre la letra es incuestionable.

29 Montero Aroca, J. Los principios políticos de la nueva Ley de Enjuiciamiento Civil. Tirant lo Blanch, Valencia, 2001. En particular, véase la sección tercera titulada «Los principios del procedimiento». 
alcanzado naturalmente a la administración de justicia, que, entre otros problemas, por ejemplo, sufre filtraciones y presiones mediáticas a través de los juicios paralelos. El ámbito de intimidad se ha visto, pues, muy reducido en el nuevo «espacio electrónico», donde cada vez nuestro escenario es más público y donde todos tenemos mayor visibilidad.

En los últimos tiempos hemos visto cambiar radicalmente las técnicas de «comunicación de ideas» (es decir, las técnicas mediante las que se materializa la comunicación de conceptos, entiéndase «el lenguaje»), y como ya hemos dicho, en la actualidad, en las escuelas no se hace ya trabajar a nuestros niños en cuestiones o técnicas de escritura, como es la caligrafía (al menos, del modo en que se les hacía trabajar hace cincuenta años) o en cuestiones gramaticales como la ortografía; estás cuestiones están dejando de ser relevantes, y pese a ello nuestra tradición en didáctica de la lengua en la escuela aún está más cerca de los llamados programas formales que de los programas basados en tareas (motivo por el que la gramática, desde una perspectiva analítica y con un cierto tono prescriptivo, es la estrella todavía de las programaciones de Lengua española), lo que todavía favorece una didáctica formal (por encima de la visión del texto como objeto de creación, cuyo estudio está todavía ausente de gran parte de las aulas) ${ }^{30}$. Por otra parte nuestro mundo más tecnificado ha incorporado a nuestro jóvenes a un modo de organizar los conocimientos más cercano a lo perceptivo-motriz que a lo hipotético deductivo ${ }^{31}$, por lo que incluso, hoy día, puede sostenerse que ha aparecido un nuevo concepto de analfabetismo, el llamado «analfabetismo tecnológico $»^{32}$ que ha cambiado el modo de concebir la comunicación y las técnicas del lenguaje.

30 Este modelo está en actual proceso de cambio y empiezan, tímidamente, a prevalecer modelos de programas procesuales que se organizan en torno a tareas de comunicación, que en la escuela pueden apuntar a la comunicación sobre los contenidos de las áreas curriculares. Sobre estos temas y el cambio en los objetivos de la enseñanza escolar de la lengua, puede verse el trabajo de Trujillo Sáez, F., «Enseñar nuevas lenguas en la escuela: L1, L2, LE..., NL», Revista de Educación, 343 (mayo-agosto 2007), pp. 71-91.

31 Sobre este aspecto además de las ideas expuestas por Sartori en su ya citado libro Homo videns..., puede verse un sencillo pero interesante trabajo de OTUZAR, I y REGIS, S., «Los jóvenes, las nuevas tecnologías y la escuela», en Razón y Palabra, 49 (febrero-marzo 2006), (conferencias magistrales dictadas en la V Bienal Iberoamericana de la Comunicación 2005, Mesa 13), en página web disponible <http://www.razonypalabra.org.mx/anteriores/n49/bienal/Mesa\%2013/ PonenciaStellaRegis.pdf,> (12/4/2017).

32 Sobre analfabetismo tecnológico ha escrito MARín, J., El analfabetismo tecnológico. Disponible en línea: <http://www.iar.unicamp.br/lab/luz/ld/Linguagem\%20Visual/el_analfabetismo_tecnologico.pdf> (12/4/2017) 
Pues bien, toda esta circunstancia que referimos respecto al lenguaje tradicional, se ha producido igualmente en el ámbito del derecho (o de la «comunicación de bienes»), donde ahora, tras la implantación de las nuevas tecnologías, resulta (sobre todo en el ámbito de gestión procesal) mucho más importante conocer los nuevos sistemas informáticos y telemáticos de gestión que las normas procesales que los regulan y, por supuesto, que cualquier otra habilidad mecanográfica (en su tiempo tan necesaria). Los nuevos «gestores procesales» deben ser conocedores de los nuevos mecanismos tecnológicos (sobre todo informáticos) a través de los cuales funciona hoy día la «nueva Oficinal Judicial». Desconocer esos mecanismos, esas nuevas tecnologías, equivale al analfabetismo. El llamado «analfabetismo tecnológico» ha alcanzado así también a nuestros órganos judiciales y a sus operadores. Los gestores procesales de hace años debían conocer muy bien las normas procesales y a lo sumo manejar diestramente la máquina de escribir (con un número mínimo de pulsaciones por minuto). Los actuales gestores procesales deben, además de conocer las normas de procedimiento, ser duchos usuarios de los principales sistemas informáticos sobre los que se apoya la actual Administración de Justicia $^{33}$.

A lo largo de los últimos años, los poderes públicos y particularmente la Administración de Justicia (entendida, en este contexto, como el servicio de

33 Entre algunas de las normas, más recientes, que han contribuido a introducir la forma de uso y el valor como instrumento jurídico de los nuevas TIC, podemos destacar las siguientes: LO 15/1999, de 13 de diciembre, de Protección de Datos de Carácter Personal. Ley 59/2003, de 19 de diciembre, de Firma Electrónica. Real Decreto 937/2003, de 18 de julio, de modernización de los archivos judiciales. Ley 11/2007, de 22 de junio, de acceso electrónico de los ciudadanos a los servicios públicos. Real Decreto 84/2007, de 26 de enero, sobre implantación de Justicia del sistema informático de telecomunicaciones Lexnet para la presentación de escritos y documentos, el traslado de copias y la realización de actos de comunicación procesal por medios telemáticos. Resolución de 24 de noviembre de 2008, de la Dirección General del Catastro, por la que se aprueba el régimen de funcionamiento de la Oficina Virtual del Catastro y de los Puntos de Información Catastral. Ley 13/2009, de 3 de noviembre de Reforma de la Legislación Procesal para la Implantación de la Nueva Oficina Judicial. Ley 18/2011, de 5 de julio, reguladora del uso de las tecnologías de la información y la comunicación en la Administración de Justicia. Ley 19/2015, de 13 de julio, de medidas de reforma administrativa en el ámbito de la Administración de Justicia y del Registro Civil. Ley 39/2015, de 1 de octubre, de procedimiento administrativo común de las Administraciones Públicas. Véase el informe recogido en el libro colectivo Las TIC en la fusticia del Futuro, Ariel, Madrid. 2009. A efectos meramente orientativos sobre la situación que ha dado en llamarse e-justicia, puede verse el artículo de GALONCHA LOZANO, E., disponible en <http://www.realsec.com/noticias/justicia-electronica-espana-situacion-actual-desafiosfuturo/> (12/4/2017) 
resolución de conflictos que el Estado pone al servicio de los ciudadanos) están incorporando, a su quehacer diario, los avances tecnológicos que la nueva era digital ha aportado para facilitar el tratamiento de la información y de la comunicación. La Administración de Justicia, no obstante, su incorporación a este proceso, lo ha hecho a un ritmo más lento del experimentado, por ejemplo, en otros ámbitos de la vida cotidiana, pero en los últimos años ha experimentado un notable incremento en el uso de las nuevas tecnologías.

El uso de las tecnologías de la información y de la comunicación en la Administración de justicia está suponiendo, sin duda, importantes beneficios en el funcionamiento de esta, no exentos de ciertos problemas inherentes a la implantación de los sistemas. Con la incorporación de los nuevos avances tecnológicos al ámbito comunicacional del Derecho, los profesionales de la justicia (desde los abogados, fiscales, procuradores, notarios, registradores, jueces etc.) han empezado a ahorrar tiempo y esfuerzo en su diario quehacer; el simple hecho de poder manejar miles de datos con mayor facilidad y celeridad, así como los nuevos sistemas de almacenamiento de información (sobre bienes, situaciones jurídicas, derechos etc.) ofrecen un horizonte a estos profesionales de mayor potencialidad, de modo que su trabajo se realiza en unas condiciones mucho más favorables, lo que permite mejores resultados a la hora de decidir, solicitar, promover... sus asuntos (o pretensiones), favoreciendo así un notable mejoramiento en el funcionamiento de toda la administración de justicia, y ofreciendo un horizonte más eficaz y eficiente a sus administrados ${ }^{34}$.

Entre otros aspectos, a destacar en este proceso de adaptación tecnológica, podemos incluso señalar que el nuevo sistema comunicacional (que empieza a aparecer cualitativamente mejorado gracias a los avances tecnológicos) permite, por ejemplo, a los justiciables relacionarse más directamente con el mecanismo

34 Hemos de indicar que pese al esfuerzo que el legislador está realizando y que se comprueba a la vista de la notable actividad legislativa que ha tenido lugar en este ámbito en los últimos tiempos (vid. nota anterior a esta), al tratarse éste de un tema, como vemos, altamente complejo, por el momento no se han podido evitar los errores y los múltiples fallos que los nuevos sistemas informáticos están generando. En particular Lexnet, sistema informático que buscaba agilizar los trámites judiciales, con su lentitud y fallos de seguridad, ha despertado las críticas de los funcionarios y de los operadores jurídicos en general. Por tanto, si bien no conviene dar una visión derrotista de los resultados que hasta ahora ha arrojado la actividad legislativa, si conviene al menos, manifestar cierta crítica a los trabajos emprendidos por la actual legislatura, para, con ello, poner de relieve la necesidad de que en un inmediato futuro se establezca una mayor colaboración, en las tareas legislativas que afectan a este ámbito, entre el poder legislativo y los usuarios naturales de estos avances tecnológicos. 
o la maquinaria instituida por parte del Estado a los efectos de «hacer justicia». Actualmente, esto se traduce, como podemos comprobar, en la posibilidad de una mayor eficiencia en el tratamiento de los casos, un ahorro de tiempo, una disminución de los costes y un más fácil acceso a una justicia de supuesta mayor calidad. En general, las nuevas tecnologías pueden facilitar que los ciudadanos logren alcanzar más cercanía respecto de la Administración encargada de este menester.

\section{CONCLUSIÓN}

Somos, pues, testigos del tránsito hacia una nueva forma de «hacer» justicia. Aunque básicamente la labor de los Tribunales sea siempre la misma (Suum cuique tribuere), las técnicas para conseguir «dar a cada uno su propio derecho» cambian conforme cambian los tiempos y ahora asistimos a un interesante cambio en la forma de operar (comunicar) los juristas, cambio, como hemos expuesto, promovido por los avances tecnológicos, un cambio que puede contribuir a que los nuevos medios de comunicación hagan más eficaz y rápida la tarea de enjuiciar, de modo tal que los procedimientos sean más breves y la información con la que resuelvan los conflictos, los operadores jurídicos, sea más veraz y exacta. Pero no hemos de olvidar por ello, dejándonos llevar por un exceso de optimismo, que todas las técnicas requieren, de una parte, del aprendizaje y, de otra, de la necesidad de que se rindan útiles al arte al que tienen vocación de servir. Por esta razón consideramos que para la formación del jurista es imprescindible en la actualidad un mínimo de conocimientos informáticos y técnicos que aparten el fantasma del «analfabetismo tecnológico» de nuestros tribunales, sin que por ello caigamos, necesariamente, en el, que podríamos llamar, «síndrome de la dictadura del sistema», consistente en ceder (o admitir) un protagonismo tal a la técnica (como en su día hizo el positivismo con la Ley) que permita que las nuevas tecnologías marquen nuestros horizontes mediante la triste y desconsoladora afirmación, a veces demasiado frecuente, de: «esto no es posible hacerlo porque el sistema o la aplicación no lo permite»; un reduccionismo de esta índole, nos podría conducir, seguramente, a la aceptación de un positivismo tecnológico hasta hoy impensable y, desde luego, mucho más pernicioso que el vivido durante el inmediato pasado. 
